OPEN ACCESS

Edited by:

Wassim El Nemer,

Institut National de la

Santé et de la Recherche

Médicale (INSERM), France

Reviewed by:

Serge Pissard,

Hôpitaux Universitaires Henri

Mondor, France

David Archer,

Emory University, United States

*Correspondence:

Abdu I. Alayash abdu.alayash@fda.hhs.gov

Specialty section:

This article was submitted to Red Blood Cell Physiology,

a section of the journal

Frontiers in Physiology

Received: 15 April 2019 Accepted: 09 July 2019

Published: 24 July 2019

Citation:

Kassa T, Wood F, Strader MB and Alayash Al (2019) Antisickling Drugs

Targeting $\beta$ Cys93 Reduce Iron Oxidation and Oxidative Changes in Sickle Cell Hemoglobin

Front. Physiol. 10:931.

doi: 10.3389/fphys.2019.00931

\section{Antisickling Drugs Targeting $\beta$ Cys93 Reduce Iron Oxidation and Oxidative Changes in Sickle Cell Hemoglobin}

\author{
Tigist Kassa, Francine Wood, Michael Brad Strader and Abdu I. Alayash*
}

Laboratory of Biochemistry and Vascular Biology, Center for Biologics Evaluation and Research, Food and Drug Administration, Silver Spring, MD, United States

Sickle cell disease is a genetic blood disorder caused by a single point mutation in the $\beta$ globin gene where glutamic acid is replaced by valine at the sixth position of the $\beta$ chain of hemoglobin $(\mathrm{Hb})$. At low oxygen tension, the polymerization of deoxyHbS into fibers occurs in red blood cells (RBCs) leading to an impaired blood vessel transit. Sickle cell hemoglobin ( $\mathrm{HbS})$, when oxidized with hydrogen peroxide $\left(\mathrm{H}_{2} \mathrm{O}_{2}\right)$, stays longer in a highly oxidizing ferryl $\left(\mathrm{Fe}^{4+}\right)$ form causing irreversible oxidation of $\beta$ Cys 93 to a destabilizing cysteic acid. We have previously reported that an antisickling drug can be designed to bind specifically to $\beta$ Cys93 and effectively protect against its irreversible oxidation by $\mathrm{H}_{2} \mathrm{O}_{2}$. Here, we report oxygen dissociation, oxidation, and polymerization kinetic reactions for four antisickling drugs (under different preclinical/clinical developmental stages) that either site-specifically target $\beta$ Cys93 or other sites on the $\mathrm{HbS}$ molecule. Molecules that specifically bind to or modify $\beta$ Cys 93 , such as 4,4'-di(1,2,3-triazolyl) disulfide (TD-3) and hydroxyurea $(H U)$ were contrasted with molecules that target other sites on $\mathrm{Hb}$ including 5-hydroxymethyl-2-furfural (5-HMF) and $\mathrm{L}$-glutamine. All reagents induced a left shift in the oxygen dissociation curve (ODC) except L-glutamine. In the presence of $\mathrm{H}_{2} \mathrm{O}_{2}\left(2.5: 1, \mathrm{H}_{2} \mathrm{O}_{2}\right.$ :heme), both TD-3 and $\mathrm{HU}$ reduced the ferryl heme by 22 and $37 \%$, respectively, which corresponded to a 3- to 2 -fold reduction in the levels of $\beta$ Cys93 oxidation as verified by mass spectrometry. Increases in the delay times prior to polymerization of $\mathrm{HbS}$ under hypoxia were in the following order: TD-3 > HU > 5-HMF = L-glutamine. Designing antisickling agents that can specifically target $\beta$ Cys93 may provide a dual antioxidant and antisickling therapeutic benefits in treating this disease.

Keywords: sickle cell anemia, hydroxyurea, L-glutamine, Endari, 4,4'-Di(1,2,3-triazolyl) disulfide (TD-3), 5-hydroxymethyl-2-furfural, cysteine 93 , polymerization

\section{INTRODUCTION}

Single amino acid replacement (glutamic acid $\rightarrow$ valine) in sickle cell disease (SCD) causes substantial reduction in the solubility of deoxyHbS leading to polymerization of tetramers into long fibers that decrease RBC membrane deformability. Distortion of the RBC into a rigid "sickle"shaped cell leads to obstruction of blood flow in the microvasculature. Sickling and unsickling 
episodes cause damage to the cell membrane, decreasing the elasticity of the cell and its ability to return to a normal biconcave disc shape when normoxic conditions are restored (unsickling) (Rees et al., 2010).

Several antisickling strategies have been proposed to avoid or to minimize sickling of RBCs by directly targeting the HbS polymerization process. This includes blocking intermolecular contacts in the fiber, inducing the synthesis of non-polymerizing fetal $\mathrm{Hb}(\mathrm{HbF})$, shifting the allosteric transition in favor of non-polymerizing HbS oxyforms, and reducing 2,3-Diphosphoglycerate and $\mathrm{HbS}$ concentrations (Eaton and Bunn, 2017).

$\mathrm{HbS}$ polymerization is believed to contribute to the molecular pathogenesis associated with acute and chronic manifestations of SCD. It is not surprising that most efforts directed toward finding a treatment have focused on the design of small antisickling molecular agents that can permeate RBCs and directly inhibit polymerization (Eaton and Bunn, 2017). It has been recognized for some time that the oxidative milieu within RBCs (in SCD patients) can be a source of toxic reactive oxygen pieces (ROS) (Mahaseth et al., 2005). Among these recently identified internal sources for ROS are NADPH oxidase subunits and mitochondria that are retained by mature SS RBCs (George et al., 2013; Jagadeeswaran et al., 2017). This extra oxidative burden within SS RBCs leads to Hb structural instability, accelerated autoxidation, and heme loss (Hebbel et al., 1988; Kassa et al., 2015). Hb oxidation side reactions within SS RBCs and RBC-derived microparticles (MPs) and the release of free $\mathrm{Hb} /$ heme further contribute to the complex disease pathophysiology (Alayash, 2018; Jana et al., 2018). Specifically, $\mathrm{Hb}$ is able to participate (inside and outside RBCs) in pseudoenzymatic radical side reactions which include the formation of a persistent and highly oxidizing ferryl state $\left(\mathrm{HbFe}^{4+}\right)$ as part of this pseudoperoxidative cycle. In addition to targeting its own $\beta$ subunits (specifically the hotspot $\beta$ Cys93), ferryl $\mathrm{Hb}$ and its associated radical $\left(\mathrm{HbFe}^{4+}\right)$ actively interact with other biological molecules (Kassa et al., 2015).

We have recently reported a newly developed reagent (di(5-(2,3-dihydro-1,4-benzodioxin-2-yl)-4H-1,2,4-triazol-3-yl) disulfide) (TD-1) that exhibits a dual antisickling and antioxidant function by shielding $\beta$ Cys 93 (the end point of radical formation in $\mathrm{HbS}$ ) in addition to its allosteric modification of $\mathrm{HbS}$ (Nakagawa et al., 2014; Kassa et al., 2017). In this study, we investigated the antisickling and antioxidant properties of several antisickling drugs that are either clinically approved for use in the USA (hydroxyurea, and L-glutamine) or currently undergoing clinical and preclinical evaluation [5HMF, and the triazol disulfide (TD-3) (an analogue for TD-1) (Abdulmalik et al., 2005; Nakagawa et al., 2018)].

The use of hydroxyurea (HU) (1), in the treatment of SCD, was approved by the Food and Drug Administration in 1998. $\mathrm{HU}$ was found to increase the amount of $\mathrm{HbF}$ in patient blood.

Abbreviations: Ferrous $\mathrm{Hb}$, Heme groups contain positively charged iron $\left(\mathrm{Fe}^{2+}\right)$ which can reversibly bind to oxygen molecules; metHb, Ferric (met) hemoglobin, the iron is in the (Fe3+); ferryl Hb, The iron is in the (Fe4+); H2O2, Hydrogen peroxide; sulfHb, Sulfhemoglobin; AA, Normal RBCs; SS, Homozygous sickle RBCs; HbS, Sickle hemoglobin; ODC, Oxygen dissociation curve; SCD, Sickle cell disease.
However, the cellular mechanism(s) by which this occurs are not completely understood, and other mechanisms may also account for the clinical benefits attributed to this agent (Ferrone, 2016). The increase in the amount of non-polymerizing $\mathrm{HbF}$ dilutes out $\mathrm{HbS}$ in patient's own RBCs that result in a decrease in the degree of polymerization and consequently relieving some of the symptoms associated with the disease (Eaton and Bunn, 2017). Another possible protection mechanism that HU may provide is through the S-nitrosylation of $\beta$ Cys 93 , which we have recently reported (Jana et al., 2018).

Endari, an oral L-glutamine therapy (2), is the another FDA approved drug intended to reduce acute complications of SCD in adults and children older than 5 years (Riley et al., 2018). Oral L-glutamine therapy has been suggested to benefit SCD patients as it potentially increases the activity of NAD synthesis, thus countering the oxidant-dependent pathophysiology of sickled RBCs. Redox potential of RBCs is defined by the ratio of NADH to the sum of NADH plus NAD+. This change in NAD redox potential decreases RBCs sensitivity to oxidative stress. This increased rate of NAD synthesis can therefore compensate for increased oxidative stress (Niihara et al., 1997).

5 -Hydroxymethylfurfural (5-HMF) (3) is a naturally occurring aromatic aldehyde that has been reported to bind to the $\mathrm{Hb}$ molecule producing a left shift in the oxygen equilibrium curve, which reduces erythrocyte sickling in animal models (Abdulmalik et al., 2005). 5HMF binds reversibly via a Schiff-base to the $\mathrm{N}$-terminal Val 1 of $\mathrm{Hb}$ alpha chains and thus allosterically modulates oxygen affinity. This agent is currently under clinical evaluation (Abdulmalik et al., 2005).

The triazole disulfide compound 4,4'-di(1,2,3-triazolyl) disulfide (TD-3) (4), which has higher aqueous solubility than TD-1 (while maintaining the ability to increase $\mathrm{Hb}$ oxygen affinity), is currently under preclinical investigation (Nakagawa et al., 2018). The crystal structures of carboxy- and deoxyforms of human adult $\mathrm{Hb}(\mathrm{HbA})$, each complexed with $\mathrm{TD}-3$, reveal that one molecule of the TD-3 monomeric thiol form forms a disulfide bond with $\beta$ Cys93, which inhibits the saltbridge formation between $\beta$-Asp94 and $\beta$-His146. This inhibition of salt bridge formation stabilizes the R-state and destabilizes the T-state of $\mathrm{Hb}$ (Nakagawa et al., 2018).

Here, we compared these four antisickling agents and found that compounds that directly or indirectly interact with $\beta$ Cys 93 prevent irreversible oxidation of cysteine to cysteic acid and provide additional protection against oxidants. It is feasible that one can therefore design new drugs targeting several processes including sickling and oxidative pathways as part of a new therapeutic modality to treat SCD.

\section{MATERIALS AND METHODS}

\section{Materials}

All chemicals and reagents were purchased from Sigma-Aldrich (Saint Louis, Missouri) or from Fisher Scientific (Pittsburgh, Pennsylvania) unless otherwise specified. Blood samples used in this study were obtained with consent from patients homozygous for $\mathrm{HbS}$ (off and on hydroxyurea treatment) during routine clinic 
visits at the National Institutes of Health (NIH), and blood from healthy donors (homozygous for $\mathrm{HbA}$ ) was also obtained from the NIH Blood Center. Hb was purified as previously described using anion and cation chromatography (Meng and Alayash, 2017). Purified sickle $\mathrm{Hb}$ was also obtained from Sigma-Aldrich. AFSC control containing mix of $\mathrm{HbA}, \mathrm{HbF}, \mathrm{HbS}$, and $\mathrm{HbC}$ was purchased from Analytical Control Systems, Inc.

\section{Experimental Procedures Measurement of Oxygen Dissociation Curves}

The oxygen dissociation curves (ODC) of suspensions of SS/ AA cells were determined with a Hemox TM Analyzer (TCS Scientific Corp.) as previously described (Kassa et al., 2017). To determine the ODC of SS cells treated with the antisickling agents, cells were washed, packed, and re-suspended in plasma to a hematocrit of approximately $20 \%$. The suspensions were incubated with 0 or $2 \mathrm{mmol} / \mathrm{L}$ antisickling agents at $37^{\circ} \mathrm{C}$ for $15 \mathrm{~min}$ (for $\mathrm{TD}-3$ ) or $1 \mathrm{~h}$ (for the rest of the agents). Approximately $120 \mu \mathrm{l}$ of each suspension was added to $3 \mathrm{ml}$ of Hemox buffer, $\mathrm{pH} 7.4$, in a cuvette and subjected to ODC analysis at $37^{\circ} \mathrm{C}$. A $120 \mu \mathrm{l}$ of the $20 \%$ AA or SS RBCs suspension with $3 \mathrm{ml}$ Hemox buffer was used as a control. Analysis was performed using triplicate samples.

\section{Measurement of $\mathrm{HbS}$ Polymerization Kinetics}

The polymerization assay was carried out using commercially available $\mathrm{HbS}$. The HbS solution was treated with the antisickling agent prior to addition to the deoxygenated buffer solution as previously reported (Kassa et al., 2017). Two equivalence ( $4.8 \mathrm{mM})$ of TD-3 and four equivalence of the 5HMF, HU, and glutamine $(9.6 \mathrm{mM})$ were used for the treatment of $\mathrm{HbS}(2.4 \mathrm{mM})$ solutions. Temperature of the treated stock HbS solutions were then dropped to $0^{\circ} \mathrm{C}$ by keeping the solution in an ice bucket. These reactions were kept at high concentration of phosphate buffer $(1.8 \mathrm{M}$, $\mathrm{pH}$ 7.3) in a $1 \mathrm{ml}$ volume sealed cuvette with nitrogen gas bubbled for $60 \mathrm{~min}$ to deoxygenate the solution. A stock $\mathrm{Hb}$ solution was then aliquoted $\left(\right.$ at $0^{\circ} \mathrm{C}$ ) in the cuvettes through a rubber septum with a Hamilton syringe to make final concentration of $\mathrm{Hb}$ in the cuvette as $120 \mu \mathrm{M}$. The cuvette was placed in a preheated sample holder in the spectrophotometer $\left(30^{\circ} \mathrm{C}\right)$. The change in turbidity was measured with a temperaturecontrolled photodiode array spectrophotometer at $700 \mathrm{~nm}$. The optical density at $700 \mathrm{~nm}$ was plotted against time to give a sigmoidal curve that shows the delay time of polymerization.

\section{Hydrogen Peroxide-Mediated Oxidation of $\mathrm{HbS}$}

The effects of antisickling agents on HbS oxidative stability were examined using a temperature-controlled photodiode array spectrophotometer (Agilent 8453, Santa Clara, California, US). $\mathrm{H}_{2} \mathrm{O}_{2}$-induced oxidation of ferrous $\mathrm{Hb}$ was monitored with and without prior treatment of $\mathrm{HbS}$ with the four antisickling agents. Determination of the $\mathrm{H}_{2} \mathrm{O}_{2}$-induced ferryl $\mathrm{Hb}$ species formation was done following our previously described method (Kassa et al., 2017). Pre-incubated HbS solution $(60 \mu \mathrm{M})$ with a given antisickling agent $(60 \mu \mathrm{M})$ at $37^{\circ} \mathrm{C}$ for the appropriate time was then brought to room temperature and subsequently treated with increasing concentrations of $\mathrm{H}_{2} \mathrm{O}_{2}(0,60,150$, 300 , or $600 \mu \mathrm{M})$ followed by incubation for $5 \mathrm{~min}$ at $25^{\circ} \mathrm{C}$. Catalase (200 units $/ \mathrm{ml}$ ) was added to the solution to terminate further oxidation reactions and remove excess $\mathrm{H}_{2} \mathrm{O}_{2}$. Absorbance spectra between 350 and $700 \mathrm{~nm}$ were measured to monitor the reaction. To determine the amount of ferryl intermediate produced, $2 \mathrm{mM}$ sodium sulfide $\left(\mathrm{Na}_{2} \mathrm{~S}\right)$ was added immediately to derivatize the ferryl heme into sulfHb that can be monitored by the appearance of absorption maxima at $620 \mathrm{~nm}$. The concentration of sulfHb was calculated using an extinction coefficient of $\varepsilon(620 \mathrm{~nm})=24.0 \mathrm{mM}^{-1} \mathrm{~cm}^{-1}$ as previously reported (Berzofsky et al., 1971).

\section{RP-HPLC Analysis of Lysates}

$\mathrm{Hb}$ solutions were prepared by lysing packed RBCs with twice their volume of water. The solution was then centrifuged at $13,000 \mathrm{rpm}$ for $5 \mathrm{~min}$ at $4^{\circ} \mathrm{C}$. RP-HPLC analyses were performed with a Zorbax $300 \mathrm{SB}$ C3 column $(4.6 \mathrm{~mm} \times 250 \mathrm{~mm})$ using a Waters HPLC system consisting of a Waters 626 pumps, 2,487 dual-wavelength detector, and 600-s controller installed with Empower 2 software (Waters Corp, Milford, MA). The supernatant, containing $\mathrm{Hb}(20 \mu \mathrm{g})$ in $25 \mu \mathrm{l}$ of water was loaded on the C3 column equilibrated with $35 \%$ acetonitrile containing $0.1 \%$ TFA (Buffer B). Globin chains were eluted with a gradient of $35-53 \%$ ACN within $80 \mathrm{~min}$ at a flow rate of $1 \mathrm{ml} / \mathrm{min}$. The eluent was monitored at $280 \mathrm{~nm}$ for globin chains and at $405 \mathrm{~nm}$ for the heme components.

\section{Quantitative Mass Spectrometric Analysis of BC93 Oxidation in $\mathrm{HbS}$}

Quantitative mass spectrometry (MS) analysis was performed utilizing $60 \mu \mathrm{M}$ (heme) HbS. To study the effect of all four antisickling agents on $\mathrm{H}_{2} \mathrm{O}_{2}$ mediated $\beta$ Cys93 amino acid oxidation, the following experimental conditions were utilized for all MS experiments described below. Experiment 1, controls: $\mathrm{HbS}$ was incubated in air equilibrated PBS buffer without $\mathrm{H}_{2} \mathrm{O}_{2}$. Experiments 2 and 3: $\mathrm{HbS}$ was incubated with 2.5 and 10 molar excess of $\mathrm{H}_{2} \mathrm{O}_{2}$ per heme. Experiments 4 and 5: HbS was incubated with each antisickling agent with 2.5 and 10 molar excess of $\mathrm{H}_{2} \mathrm{O}_{2}$ per heme. All oxidation reactions were carried out in phosphate buffer saline (PBS), pH 7.4 at ambient temperature for $30 \mathrm{~min}$. One microliter of $1 \mathrm{unit} / \mu \mathrm{l}$ catalase was added to remove excess $\mathrm{H}_{2} \mathrm{O}_{2}$ to quench oxidation from samples listed in experiments 2-5.

\section{LC-MS/MS Analysis}

All HbS samples (listed above in experiments 1-5) were digested with trypsin, desalted, and analyzed by mass spectrometry as previously described (Strader et al., 2014). Briefly, tryptic peptides were analyzed by reverse phase liquid chromatography mass spectrometry (RP LC/MS/MS) using an Easy nLC II Proxeon nanoflow HPLC system coupled online to a Q-Exactive Orbitrap mass spectrometer (Thermo Scientific). Data were acquired using a top10 method (for $60 \mathrm{~min}$ ), dynamically choosing the most abundant precursors (scanned at $400-2,000 \mathrm{~m} / \mathrm{z}$ ) from the survey scans for HCD fragmentation. 
Mass spectrometry was also used to confirm that HbS control samples were catalase free by searching data against the SwissProt Human database (release 2014_03, containing 542,782 sequence entries) supplemented with the porcine trypsin sequence using the Mascot (version 2.4) search engine (Matrix Sciences, London, UK) as described previously (Strader et al., 2014). Variable modifications including cysteine trioxidation (+48 Da), methionine oxidation (+16), and S-nitrosylation (+29 Da; for hydroxyurea samples) were included for identifying oxidative modifications. Mascot output files were analyzed using the software Scaffold 4.2.0 (Proteome Software Inc.). Hb peptide identifications were accepted if they could be established at greater than $99.9 \%$ probability and contained at least two identified peptides. Probabilities were assigned by the Protein Prophet algorithm (Keller et al., 2002).

\section{Intact Mass Analysis}

Subunits of intact $\mathrm{HbS}$ with either 5-HMF or TD-3 adducts were isolated using RP-HPLC prior to LC-MS analysis. Samples were analyzed using a Q-Exactive as described above with the instrument configured to acquire data in full-MS mode with a resolution of 140,000 full width half maximum (FWHM). Isotopically resolved charge state envelopes (multiply charged ions of intact monomers) representing mass spectra of intact $\mathrm{Hb}$ subunits were deconvoluted using the protein deconvolution software Xtract (Thermo Scientific). The deconvoluted mass spectrum yielded a measured molecular mass that was within $0.025 \mathrm{Da}(3 \mathrm{ppm})$ of the calculated value.

\section{Quantitative MS Analysis}

Peptides from LC-MS/MS data were analyzed to quantify changes in $\mathrm{Hb}$ under oxidative conditions as previously described (Strader et al., 2014). Each peptide was further validated by retention time reproducibility. All quantitative experiments were performed in triplicate, and standard deviations were obtained by averaging relative abundance data from three different experiments. Extracted ion chromatograms (XICs) were generated from the most abundant monoisotopic peak of isotopic profiles representing charged states of each peptide (oxidized and unoxidized). To construct XICs, Xcalibur (version 2.4) software was used with a designated mass tolerance of $0.01 \mathrm{Da}$, and mass precision set to three decimals. For relative quantification, the ratio of each isoform was calculated based on the sum of the XIC peak area from all forms, which was normalized to $100 \%$ and included all charge states and versions that result from different cleavage sites.

\section{RESULTS}

\section{Measurements of Oxygen Dissociation Curves}

Effects of the four antisickling agents on the oxygen affinity of normal AA and SS RBCs were studied. Incubation of normal AA cells $(20 \% \mathrm{Hct})$ with increasing concentrations of TD-3 $(0,0.5,1$, and $2 \mathrm{mM})$ shifted the ODC to the left in a dosedependent manner (Figure 1A). Treatment of the RBCs with
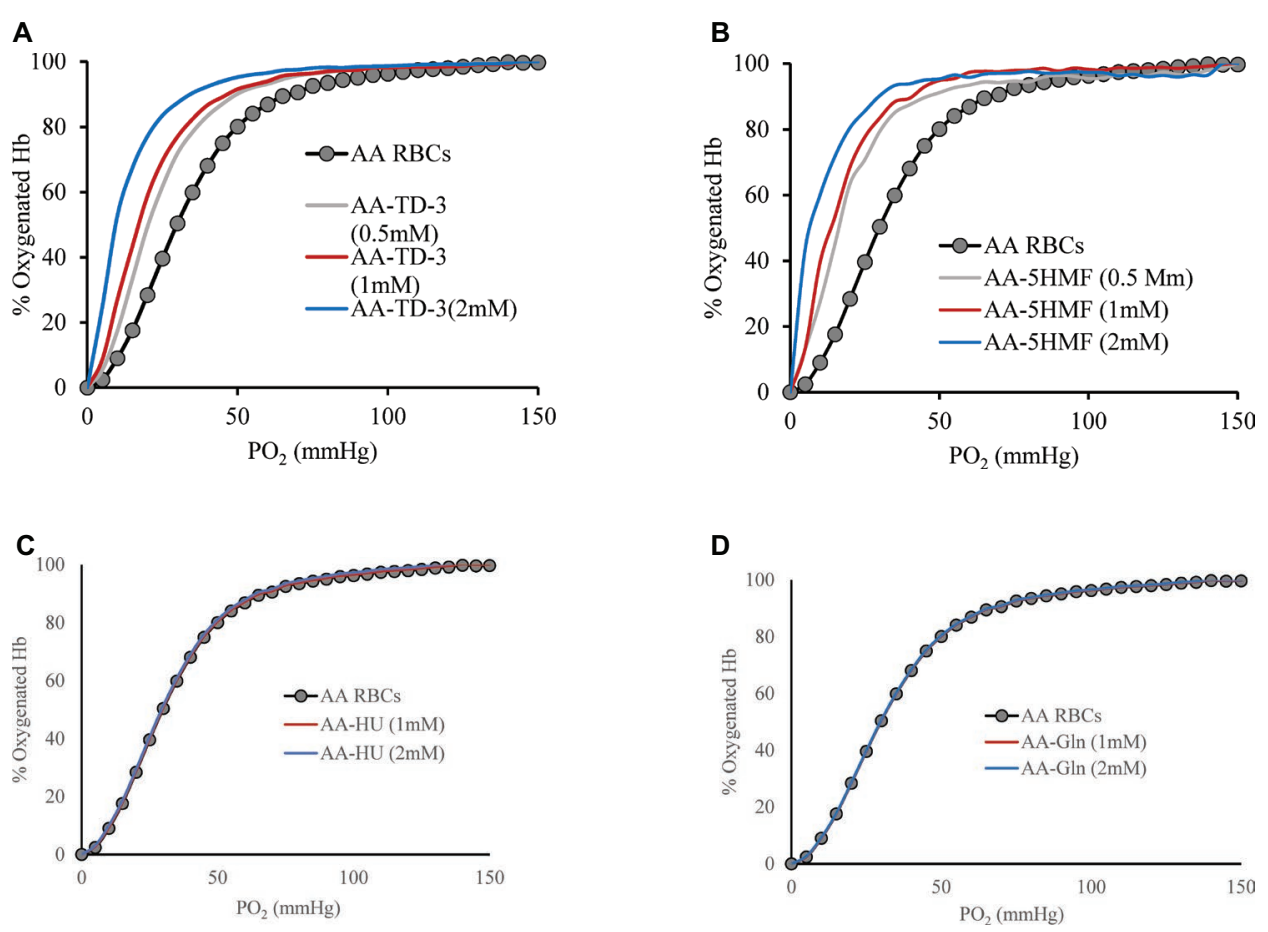

FIGURE 1 | The effect of antisickling agent on the ODCs of AA intact cells. Suspensions of AA cell hematocrit (20\%) were incubated in the presence of various concentrations of antisickling agent at $37^{\circ} \mathrm{C}$ for $15 \mathrm{~min}$ (TD-3) or $1 \mathrm{~h}$ (the other antisickling agents) prior to determination of the ODC using Hemox Analyzer. Oxygen dissociation curves (ODC) of AA cells with increasing molar ratio of TD-3, 5HMF, HU, and glutamine to Hb in heme are shown in (A), (B), (C), and (D), respectively. 
the highest TD-3 dose $(2 \mathrm{mM})$ resulted in a $P_{50}$ reduction from 28.4 to $9.8 \mathrm{mmHg}$. Similar reduction in $P_{50}$ values was observed in the ODCs of SS cells that had been pre-incubated with TD-3 (2 mM) (Figure 2A); the $P_{50}$ value of the SS cells was reduced from 34.2 to $9.6 \mathrm{mmHg}$. These results demonstrated the ability of TD-3 to permeate through RBC membranes and to interact with intracellular $\mathrm{HbS}$, consistent with early reports (Nakagawa et al., 2018). In the absence of TD-3 (control), the ODC of $\mathrm{Hb}$ solutions (data not shown) and RBCs showed a typical sigmoid curve; however, pre-incubation of cells with TD-3 induced a change in shape of the curve from sigmoid to hyperbolic with increasing TD-3 concentrations, indicating a loss in cooperativity as reflected by reduced values of the Hill coefficients (as shown in Table 1).

The effect of 5HMF on oxygen affinity of intact RBCs was also studied under the same experimental conditions described above. There was a reduction in the $P_{50}$ from 28.4 to $8.7 \mathrm{mmHg}$ when AA cells were treated with 5HMF (Figure 1B). Similarly, a reduction in the $P_{50}$ value derived from ODCs of SS cells pre-incubated with 5HMF (2 mM) was observed (Figure 2A); the $P_{50}$ value of the SS cells was reduced from 34.2 to $10.8 \mathrm{mmHg}$. We observed changes not only in the position but also in the shape of ODC with increasing concentrations of 5HMF.

In vitro incubation of AA or SS RBCs $(20 \% \mathrm{Hct})$ with $\mathrm{HU}$ or L-glutamine $(2 \mathrm{mM})$ did not induce a shift (left or right) in the ODCs as shown in Figures 1C,D. Similarly, no effects on the ODCs were observed with purified $\mathrm{Hb}$ (data not shown). To demonstrate the long-term effects on $\mathrm{HbF}$ induction by HU in vivo, we measured the ODC of HU-treated patient blood samples which showed a clear left shift in the ODC compared to a sample from SS patient who was not on $\mathrm{HU}$ treatment (Figure 2B). The $P_{50}$ value had decreased from 40.95 to $32.51 \mathrm{mmHg}$, respectively. This reduction in $P_{50}$ value and the left shift is attributed to the presence of $\mathrm{HbF}$ in the patient's blood. This result was further confirmed by RP-HPLC analysis. For these experiments, the $\mathrm{HU}$-treated patient lysate revealed the presence of $\mathrm{HbF} \gamma$ subunits $(\sim 20 \% \mathrm{HbF})$. Under our chromatographic conditions, the heme component for all samples had an elution time of $15 \mathrm{~min}$ whereas $\beta$ and $\alpha$ chains of $\mathrm{HbA}$ eluted at 38 and $44 \mathrm{~min}$, respectively, and the $\beta$ and $\alpha$ chains of $\mathrm{HbS}$ eluted at 40 and $44 \mathrm{~min}$, respectively. The $\beta^{\mathrm{C}}, \gamma^{\mathrm{G}}$, and $\gamma^{\mathrm{A}}$ eluted at 36, 48, and $50 \mathrm{~min}$, respectively (Figure 2C). However, the profile of lysates from the patient who was not on $\mathrm{HU}$ treatment did not show much of the $\gamma$ subunit peak. $P_{50}$ and Hill coefficient values for HU or glutamine-treated RBCs are listed in Table $\mathbf{1 .}$

\section{Effects of Antisickling Reagents on the Polymerization Kinetics of HbS}

HbS polymerization begins with a prominent latency period, called a "delay time" followed by abrupt polymer formation (Eaton and Bunn, 2017). Previous studies have shown that an increase in the concentration dependent delay time for $\mathrm{HbS}$ polymer formation has a therapeutic effect (Mozzarelli et al., 1987)
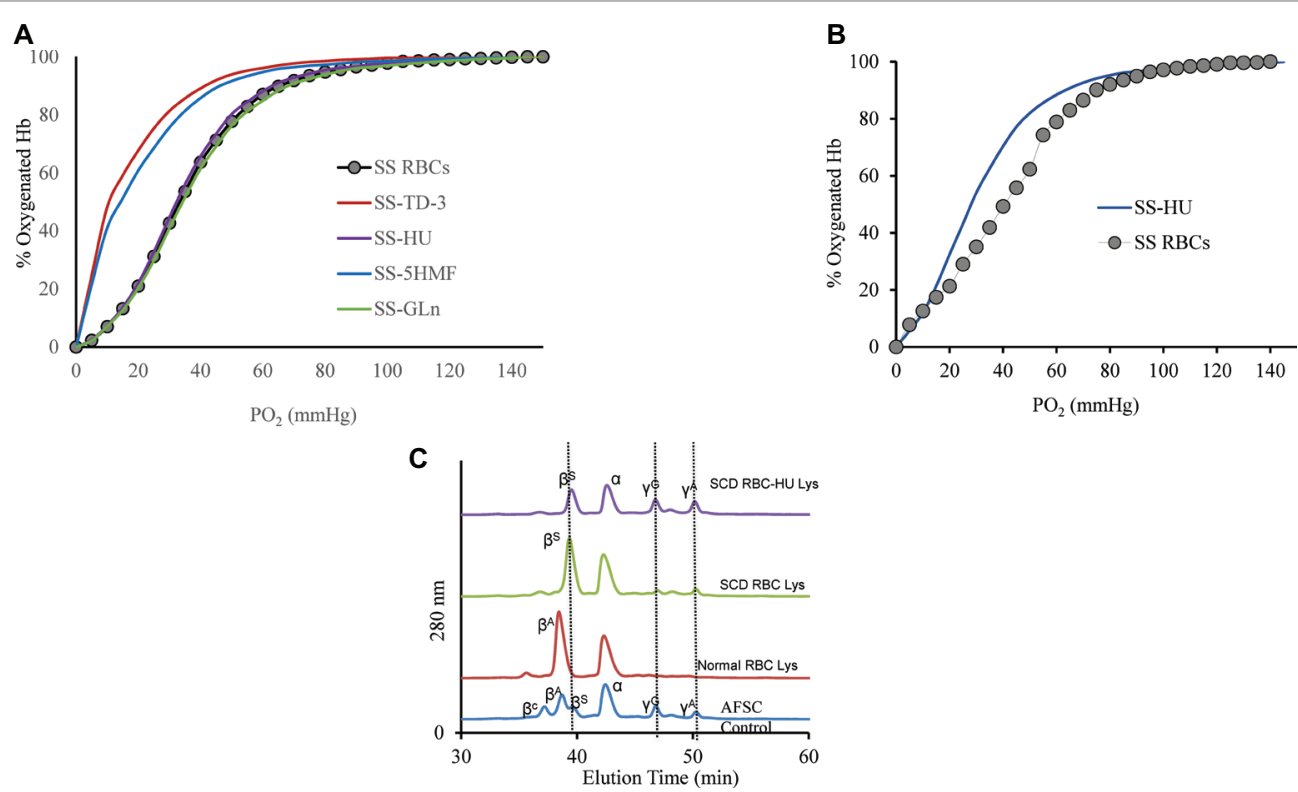

FIGURE 2 | Oxygen dissociation curves (ODC) of SS intact cells after treatment with the antisickling agents. (A) Suspensions of SS cells [hematocrit (20\%)] were incubated in the presence of antisickling agent at $37^{\circ} \mathrm{C}$ for $15 \mathrm{~min}$ (TD-3) or $1 \mathrm{~h}$ (the other antisickling agents) prior to determination of the ODC using Hemox Analyzer. Oxygen dissociation curves (ODC) of SS cells with $2 \mathrm{mM}$ TD-3, 5HMF, HU, or glutamine is shown in the Figure. (B) Left-shift of the oxygen dissociation curve (ODC) of sickle cell patient blood who was on HU compared to patient who was not on treatment of HU. (C) RP-HPLC data of lysate from patient with and without $\mathrm{HU}$ treatment. $\mathrm{Hb}(0.96 \mathrm{mg})$ was injected into $\mathrm{C} 3$ column. The mobile phase consisted of (1) $0.1 \%$ TFA in water and (2) $0.1 \%$ TFA in acetonitrile. A gradient was programmed to increase from 35 to $53 \%$ Buffer B over 80 min. Solvents were mixed and run at a rate of $1 \mathrm{ml} / \mathrm{min}$ and absorbance was monitored at 280 and $405 \mathrm{~nm}$. AFSC is monitored at 280 and is shown as control. 
by virtue of preventing most cells from sickling in vivo. We tested the polymerization kinetics of treated and untreated oxyHbS with all four antisickling agents. Delay time results for treated samples were compared with non-treated $\mathrm{HbS}$ samples and are presented in Figure 3. Our results indicate that all four antisickling agents increased the delay time when compared with control $\mathrm{HbS}$. The delay time plot (absorbance changes at $700 \mathrm{~nm}$ as a function of time) for HbS treated with TD-3 was shifted to the right of the HbS control (Figure 3A). The delay time for the untreated and TD-3 treated $\mathrm{HbS}$ was 315 and $630 \mathrm{~s}$, respectively. These results suggest that TD-3 increased the delay time by $315 \mathrm{~s}$ indicating that TD-3 treated $\mathrm{HbS}$ polymerizes slower than the untreated HbS (control). The same trend was observed with the other antisickling agents. HU increased the delay time by $170 \mathrm{~s}$ while both 5HMF and glutamine increased the delay time by $158 \mathrm{~s}$. Taken together, these data confirm that these antisickling agents inhibit in vitro $\mathrm{HbS}$ polymerization and suggest that they may also delay in vivo $\mathrm{HbS}$ polymerization.

\section{Hydrogen Peroxide-Induced Oxidation of $\mathrm{HbS}$}

In the presence of $\mathrm{H}_{2} \mathrm{O}_{2}, \mathrm{Hb}$ is transformed into the higher oxidation ferryl $\mathrm{Hb}\left(\mathrm{Fe}^{4+}\right)$ form and the globin associated radical. Both the ferryl $\mathrm{Hb}\left(\mathrm{Fe}^{4+}\right)$ form and the globin-associated radical are strong oxidants that can induce irreversible oxidation of "hotspot" amino acids near the heme region with $\beta$ Cys93 being the most impacted. The irreversible oxidation of $\beta$ Cys 93 to cysteic acid in the presence of $\mathrm{H}_{2} \mathrm{O}_{2}$ destabilizes $\mathrm{Hb}$ (Kassa et al., 2015). In this study, we estimated ferryl heme levels that were formed with $\mathrm{H}_{2} \mathrm{O}_{2}$ treatment in the presence and absence of each antisickling agent. Sodium sulfide was used to derivatize the transient ferryl $\mathrm{Hb}$ to a stable sulfHb intermediate that could then be spectrophotometrically measured.

TABLE 1 | Oxygen equilibrium data for RBCs treated with antisickling agents.

\begin{tabular}{|c|c|c|c|c|c|c|}
\hline $\begin{array}{l}\text { Antisickling agent } \\
(2 \mathrm{Mm})\end{array}$ & $\begin{array}{c}\text { AA cells }(25 \% \text { Hct }) \\
P_{50}(\mathrm{mmHg})\end{array}$ & $\begin{array}{c}\text { AA cells } \\
\Delta P_{50}(\mathrm{mmHg})\end{array}$ & $\begin{array}{l}\text { AA cells Hill } \\
\text { coefficient }(n)\end{array}$ & $\begin{array}{c}\text { SS cells }(25 \% \text { Hct }) \\
P_{50}(\mathrm{mmHg})\end{array}$ & $\begin{array}{c}\text { SS cells } \\
\Delta P_{50}(\mathrm{mmHg})\end{array}$ & $\begin{array}{l}\text { SS cells Hill } \\
\text { coefficient }(n)\end{array}$ \\
\hline Control (0) & $28.4 \pm 0.19$ & - & $2.81 \pm 0.07$ & $34.2 \pm 0.71$ & - & $2.86 \pm 0.02$ \\
\hline TD-3 & $9.8 \pm 0.30$ & 18.6 & $1.66 \pm 0.01$ & $9.6 \pm 0.40$ & 24.6 & $1.67 \pm 0.03$ \\
\hline $5 \mathrm{HMF}$ & $8.7 \pm 0.21$ & 19.7 & $1.25 \pm 0.04$ & $10.8 \pm 1.26$ & 24.1 & $1.39 \pm 0.05$ \\
\hline $\mathrm{HU}$ & $28.1 \pm 0.02$ & 0.3 & $2.86 \pm 0.03$ & $33.97 \pm 0.57$ & 0.23 & $2.86 \pm 0.04$ \\
\hline Gln & $28.1 \pm 0.08$ & 0.3 & $2.84 \pm 0.04$ & $33.73 \pm 0.47$ & 0.47 & $2.86 \pm 0.04$ \\
\hline
\end{tabular}

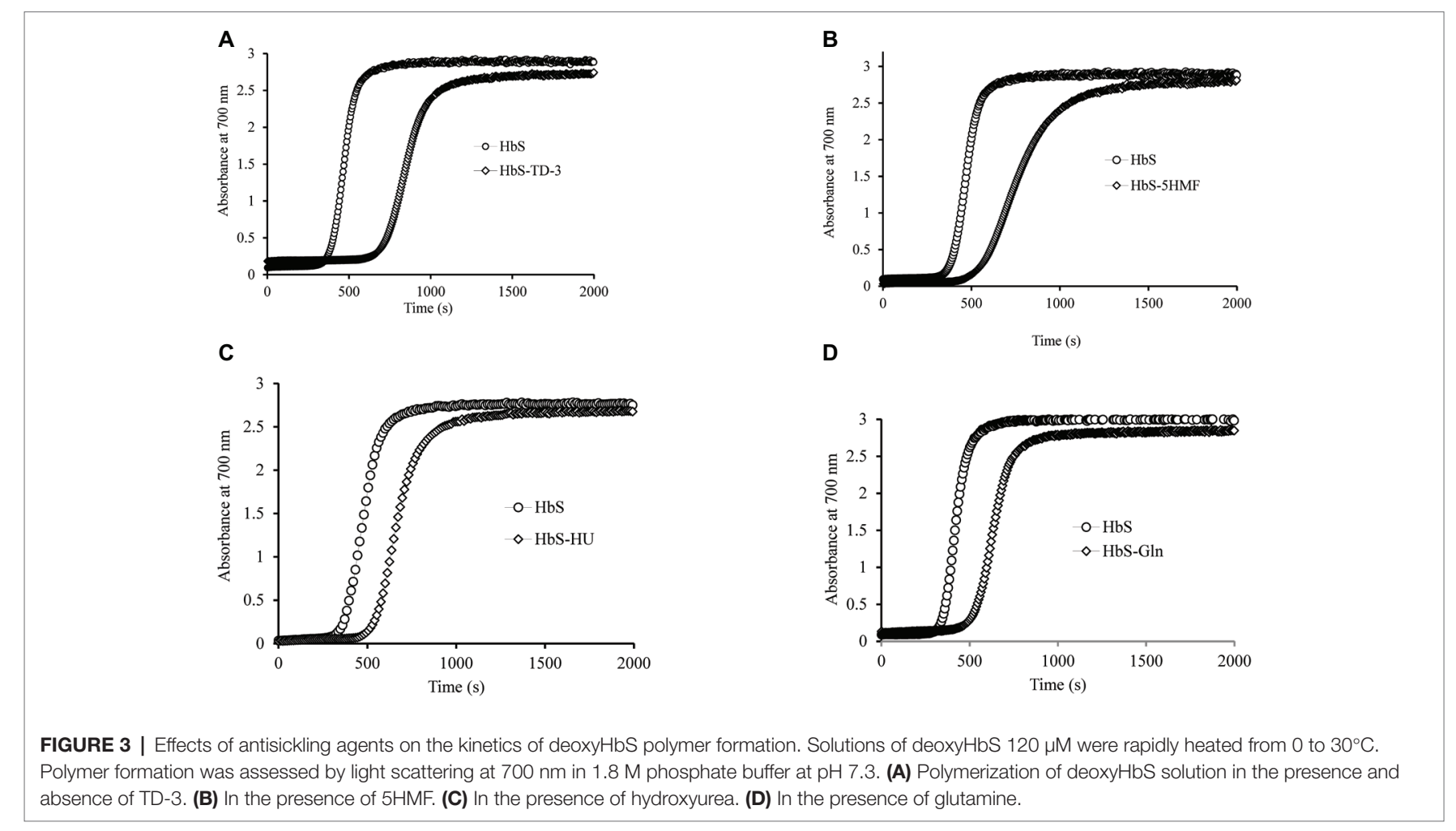


A typical spectral transition of the reaction of ferrous $\mathrm{HbS}$ $(60 \mu \mathrm{M})$ with $\mathrm{H}_{2} \mathrm{O}_{2}(150 \mu \mathrm{M})$ representing ferryl formation and its conversion to sulfHb is shown in Figure 4A. Figure 4B shows sulfHb levels in $\mathrm{HbS}$ solutions treated with TD-3 in the presence of increasing concentrations of $\mathrm{H}_{2} \mathrm{O}_{2}$. The levels of sulfHb produced from $\mathrm{TD}$-3-treated $\mathrm{HbS}$ are lower than that of the non-treated $\mathrm{HbS}$ at all concentrations of $\mathrm{H}_{2} \mathrm{O}_{2}$ $(p \leq 0.5)$. Similar trends were seen in the HU-treated samples in response to increasing $\mathrm{H}_{2} \mathrm{O}_{2}$ concentrations. Figure $4 \mathrm{C}$ compares the effects of all antisickling agents on the amount of ferryl produced with the reaction of $\mathrm{H}_{2} \mathrm{O}_{2}$ (at a ratio of $\mathrm{H}_{2} \mathrm{O}_{2}: \mathrm{Hb}$ of 2.5:1). The results summarized in Table 2 indicate that $\mathrm{HbS}$ treatment with TD-3 and HU reduced ferryl levels by 22 and 37\%, respectively, confirming the antioxidant property of these antisickling agents. 5HMF and L-glutamine, on the other hand, showed no effects on ferryl $\mathrm{Hb}$ levels produced by the treatment with $\mathrm{H}_{2} \mathrm{O}_{2}$.

\section{Mass Spectrometric Analysis to Evaluate Antioxidant Properties of Anti-Sickling Agents}

Using mass spectrometric analysis, we first verified the binding of these antisickling agents to HbS. Figure 5 shows that TD-3, $5 \mathrm{HMF}$, and HU modified HbS. For example, Panel A and B show intact mass (top-down) data confirming that TD-3 interacted with the $\beta$ subunit and $\alpha$ subunit, respectively. These results support previous studies that linked the TD-3 modification specificity to $\beta$ Cys93 (Nakagawa et al., 2018); this report is the first however to show that TD-3 also modifies the a subunit. Similar $\beta$ Cys 93 oxidation levels from this study at both $2.5 \mathrm{X}$ and $10 \mathrm{X} \mathrm{H}_{2} \mathrm{O}_{2}$ conditions (see below) also correlate with the intact mass data indicating that the TD-3 $\beta$ subunit modification stoichiometry was likely similar for both conditions.
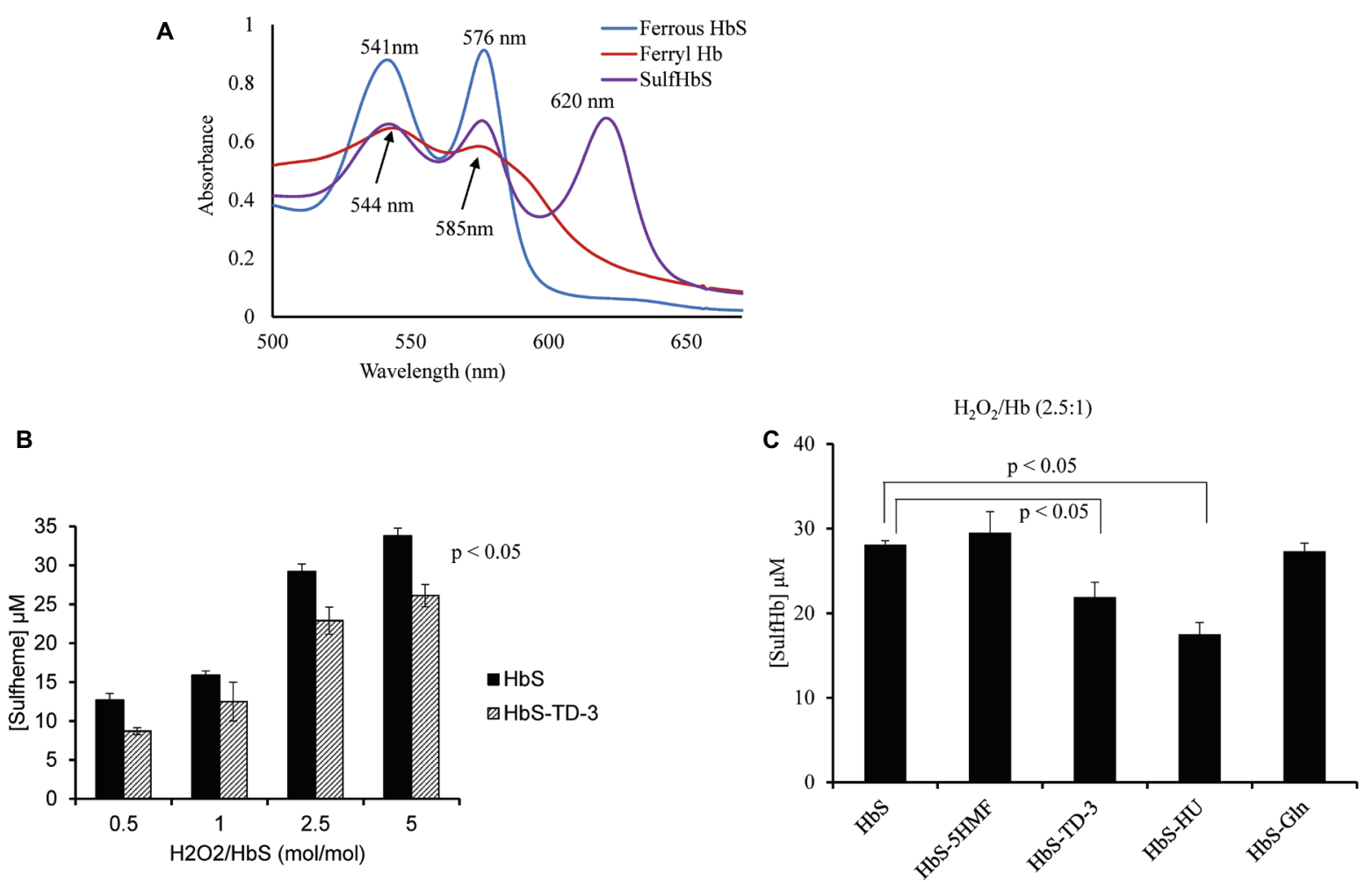

FIGURE 4 | Spectral analysis of TD-3 effect on ferryl hemoglobin formation. (A) Absorbance spectra obtained upon treatment of HbS (60 $\mu \mathrm{M})$ (blue line) with $150 \mu \mathrm{M}$ $\mathrm{H}_{2} \mathrm{O}_{2}$. Ferryl $\mathrm{Hb}$ spectrum (red) is characterized by new emerging peaks at 544 and $585 \mathrm{~nm}$, respectively, and a flattened region between 600 and $700 \mathrm{~nm}$. Absorbance spectra obtained immediately after addition of $\mathrm{Na}_{2} \mathrm{~S}(2 \mathrm{mM}$ ) to convert $\mathrm{HbS}$ to sulfHb (purple) that exhibits a characteristic strong peak at $620 \mathrm{~nm}$. (B) Levels of sulffHb are plotted in a bar graph; non-treated $\mathrm{HbS}$ (black) and TD-3 treated (pattern). (C) Sulfheme levels produced from HbS treated with the antisickling agents.

TABLE 2 | SulfHb produced by the reaction of hydrogen peroxide $(\mu \mathrm{M})$ with sickle $\mathrm{Hb}$ in the presence and absence of antisickling agent.

\begin{tabular}{lcccc}
\hline $\mathbf{H}_{\mathbf{2}} \mathbf{O}_{\mathbf{2}} \mathbf{H b}$ & HbS & HbS-TD-3 (\% Reduction) & HbS-5HMF & HbS-HU (\% Reduction) \\
\hline 0.5 & $12.7 \pm 0.55$ & $8.7 \pm 0.95(31.5 \%)$ & $13.2 \pm 1.45$ & $8.0 \pm 1.41(37.0 \%)$ \\
1 & $23.9 \pm 0.45$ & $12.5 \pm 0.96(47.7 \%)$ & $24.2 \pm 1.82$ & $10.4 \pm 1.05(56.5 \%)$ \\
2.5 & $28.1 \pm 0.45$ & $21.9 \pm 1.74(22.1 \%)$ & $29.5 \pm 2.50$ & $17.5 \pm 1.42(37.7 \%)$ \\
5 & $38.9 \pm 0.44$ & $26.1 \pm 1.45(32.9 \%)$ & $36.4 \pm 2.15$ & $23.9 \pm 1.22(38.6 \%)$
\end{tabular}



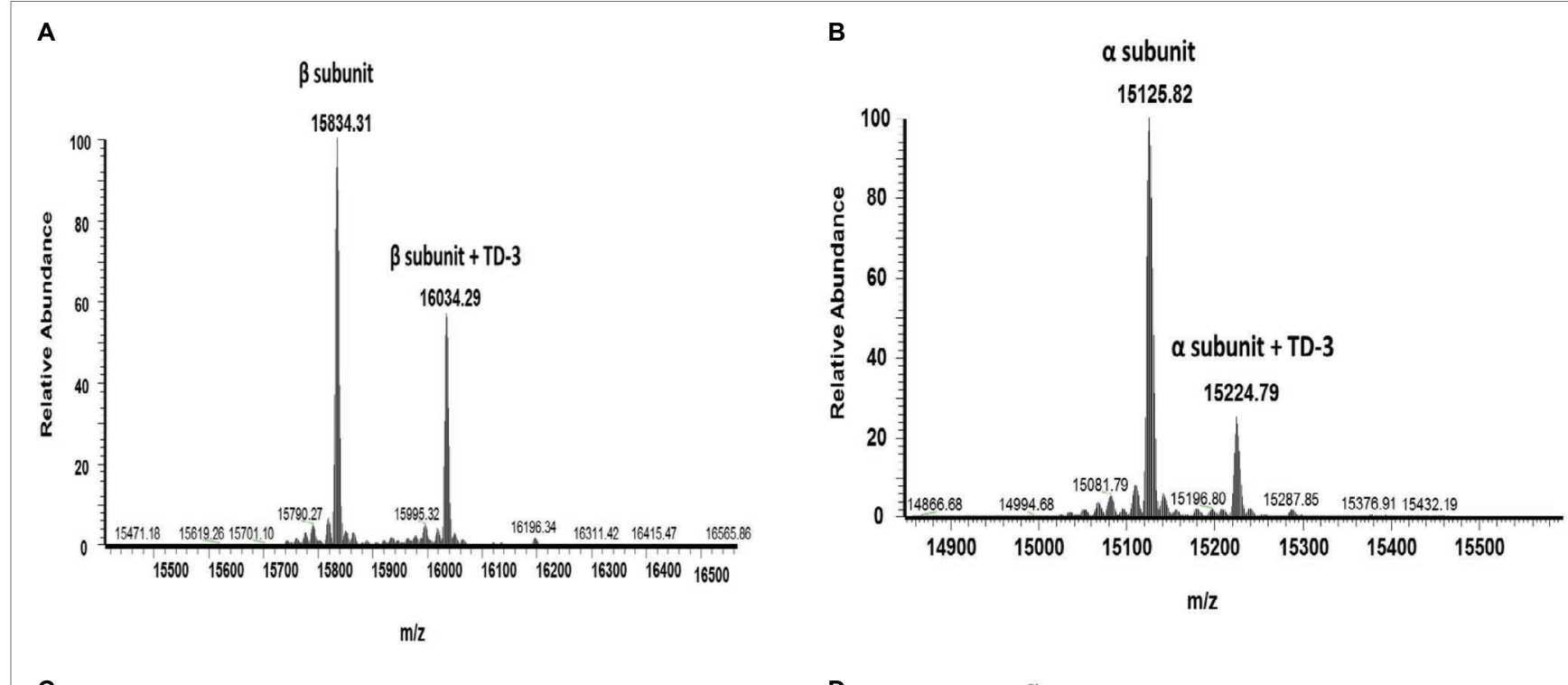

C
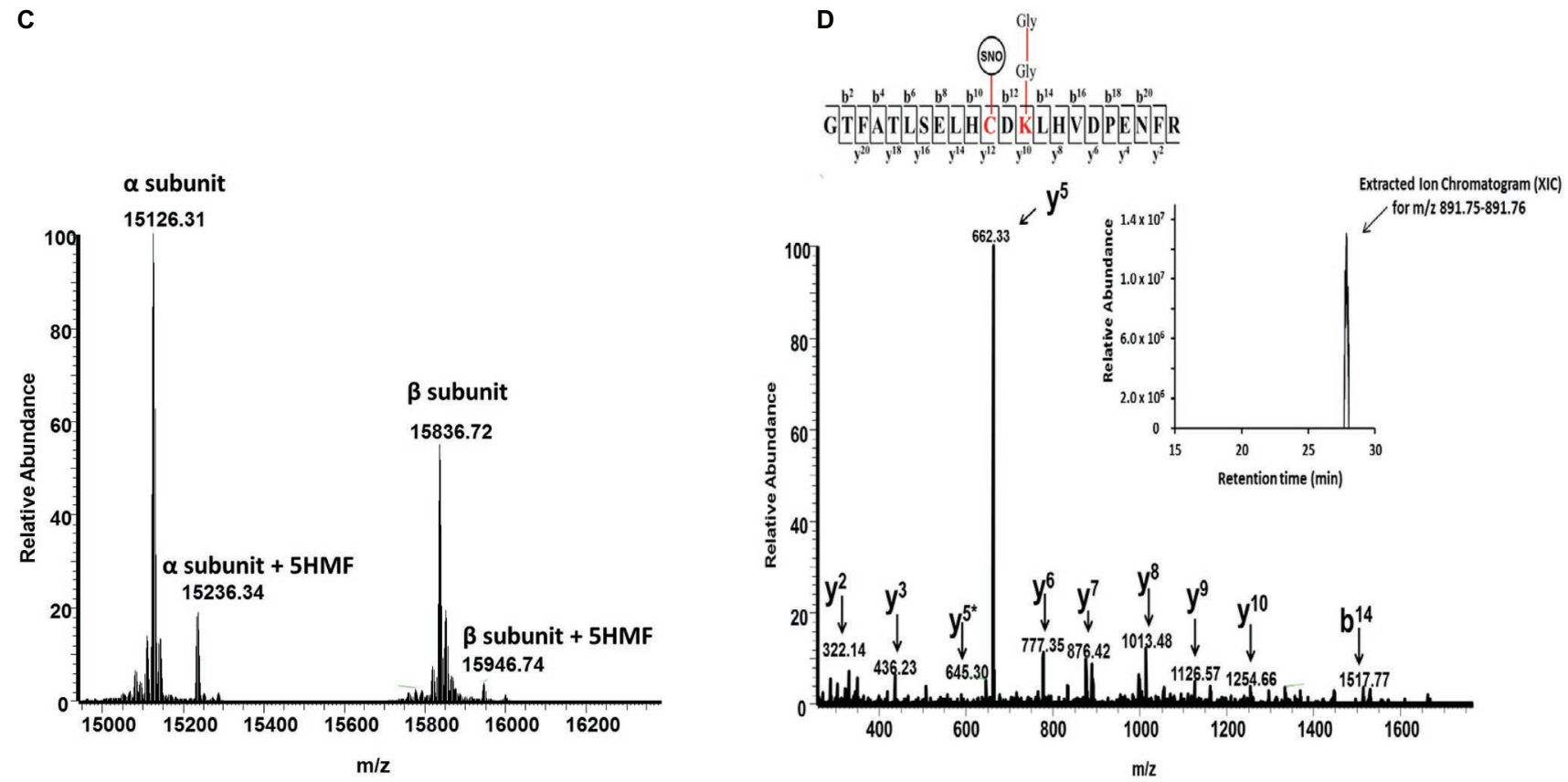

FIGURE 5 | Representative mass spectrometry data confirming the modification of HbS by TD-3, 5HMF, and HU. Intact mass (top-down) and LC/MS/MS (bottom-up) analysis were utilized to elucidate how the antisickling reagents interact with $\mathrm{HbS}$. (A and $\mathbf{B}$ ) Intact mass data confirm that TD-3 substantially modifies both $\beta$ and $\alpha$ subunits. (C) Intact mass data confirms that 5HMF modifies both $\alpha$ and $\beta$ subunits. (D) MS/MS fragmentation spectrum representing the $y$ and $b$ ions matched to the modified tryptic peptide GTFATSELHCDKLHVDPENFR (residues 83-104) from HbS incubated with HU. This peptide contains the diglycine signature modification (at $\beta$ K96) associated with ubiquitination and S-nitrosylation (at $\beta C 93$ ). The inset represents the extracted ion chromatogram representing the S-nitrosylated peptide.

Figure $5 \mathrm{C}$ also confirms previous reports that $5 \mathrm{HMF}$ reacts specifically with a N-termini (Abdulmalik et al., 2005). Our data are the first to also show that 5HMF also forms a covalent bond with the $\beta \mathrm{N}$-terminus. Finally, Figure 5D shows the LC/MS/MS fragmentation spectrum (bottom-up) and corresponding inset representing the extracted ion chromatogram of the S-nitrosylated peptide (i.e., addition of $29 \mathrm{Da}$ ) supporting our earlier studies which link HU treatment to $\beta$ C93 specific S-nitrosylation (Jana et al., 2018). It has previously been established that the surface amino acid $\beta$ Cys 93 is an endpoint for free radical induced $\mathrm{Hb}$ oxidation and consequently incurs prevalent $\mathrm{H}_{2} \mathrm{O}_{2}$ induced oxidative changes (Jia et al., 2007; Pimenova et al., 2010; Strader and Alayash, 2017). Additionally, we have previously shown, via LC/MS/MS analysis, that HbS oxidative toxicity (compared to $\mathrm{HbA}$ ) is linked to irreversible $\beta \mathrm{C} 93$ oxidation to cysteic acid at the amino acid side chain (Kassa et al., 2015). Next, LC/MS/MS quantification of $\beta$ Cys 93 oxidation was therefore utilized (as an "oxidation reporter") to evaluate the potential antioxidant properties of each antisickling agent. 
For each $\beta$ Cys93 containing peptide charge state identified by Mascot database searches (see Table 3), extracted ion chromatograms (XICs) were generated from the most abundant monoisotopic peak of each peptide isotopic profile, and the resulting ratio differences were compared. For example, the most abundant mono-isotopic peak $(645.31 \mathrm{~m} / \mathrm{z})$ in Figure 6A for the oxidized $+4 \beta$ Cys93 peptide, GTFATLSELHCDKLHVDPENFR, (treated with $10 \mathrm{X}_{2} \mathrm{O}_{2}$ ) was used to construct the XIC shown in Figure 6B. Because $\beta$ Cys93 exists in either the oxidized or unoxidized form after treatment with $10 \mathrm{X} \mathrm{H}_{2} \mathrm{O}_{2}$, the relative abundance of both isoforms was calculated based on the sum of the XIC peak area from all charged isoforms of $\beta$ Cys 93 peptides. For each experimental condition analyzed by LC/MS/ MS, XICs were generated in a similar manner (for all $\beta$ C93 peptide charge states listed in Table 3), and the XIC peak area integration values were determined for relative quantification as previously described (Kassa et al., 2015; Strader and Alayash, 2017; Meng et al., 2019). Table 4 represents the calculated ratio values for these studies based on the sum of XIC numerically integrated peak area of all $\beta$ Cys 93 peptide charge states (oxidized and unmodified) to be $100 \%$. As shown in this table, $\mathrm{H}_{2} \mathrm{O}_{2}$ addition (2.5- and 10-fold in excess) led to increased $\beta$ C93 oxidation; the level of oxidation in the controls was similar to our previous HbS study (Kassa et al., 2015). With the exception

TABLE 3 | C93 peptides including different charge states.

\begin{tabular}{llcc}
\hline Peptides & $\begin{array}{l}\text { Modified } \\
\text { residue }\end{array}$ & $\begin{array}{c}(+) \text { Charge } \\
\text { state }\end{array}$ & $\mathbf{m} / \mathbf{z}$ \\
\hline${ }^{8}$ GTFATLSELHCDK $^{96}$ & $\beta C y s 93$ & 2 & 735.33 \\
${ }^{8}$ GTFATLSELHCDKLHVDPENFR $^{104}$ & $\beta$ Cys93 & 3 & 860.06 \\
& & 4 & 645.31 \\
& & 5 & 518.25
\end{tabular}

of glutamine and 5HMF, the other two agents (TD-3 and HU) reduced $\beta$ C93 oxidation by providing anti-oxidant protection; TD-3 modification resulted in the most substantial decrease in $\beta$ C93 oxidation (by $\sim 3$-fold) followed by $\mathrm{HU}$ which reduced $\beta$ C93 oxidation by $\sim 2$-fold.

\section{DISCUSSION}

The sickling/unsickling cycles in the microvasculature result in greater (almost 2-fold) amounts of ROS (mainly $\mathrm{O}_{2}^{-}$, and $\mathrm{H}_{2} \mathrm{O}_{2}$ ) that accumulate within SS RBCs (Jana et al., 2018). Consequently, $\mathrm{RBC}$ antioxidative enzyme activities (primarily SOD and catalase) increase in response to ROS-induced oxidative stress. Increased expression of NADPH oxidase-derived ROS (George et al., 2013) and the retention of active mitochondria in mature RBCs may also cause direct oxidative damage to a variety of subcellular structures which ultimately leads to increased RBC fragility and hemolysis (Jagadeeswaran et al., 2017). We have recently shown that changes in antioxidative enzymes and consequent posttranslational changes in the $\mathrm{Hb}$ molecule extend into the RBC-derived MPs that are circulating in sickle cell blood (Jana et al., 2018). These $\mathrm{Hb}$-dependent oxidation reactions were also found to drive cytosolic internal and RBC membrane changes including alternation in band 3 activities.

Despite our growing mechanistic understanding of $\mathrm{HbS}$ polymerization and the resulting effects on RBCs in circulation, current treatment options do not fully address the complex molecular manifestations of SCD. It was recently suggested, however, that systems-oriented multi-agent strategies should be developed to counter the multifaceted aspects of this disease by designing new drugs targeting several of these processes. This includes agents that reactivate $\mathrm{HbF}$, anti-sickling agents,

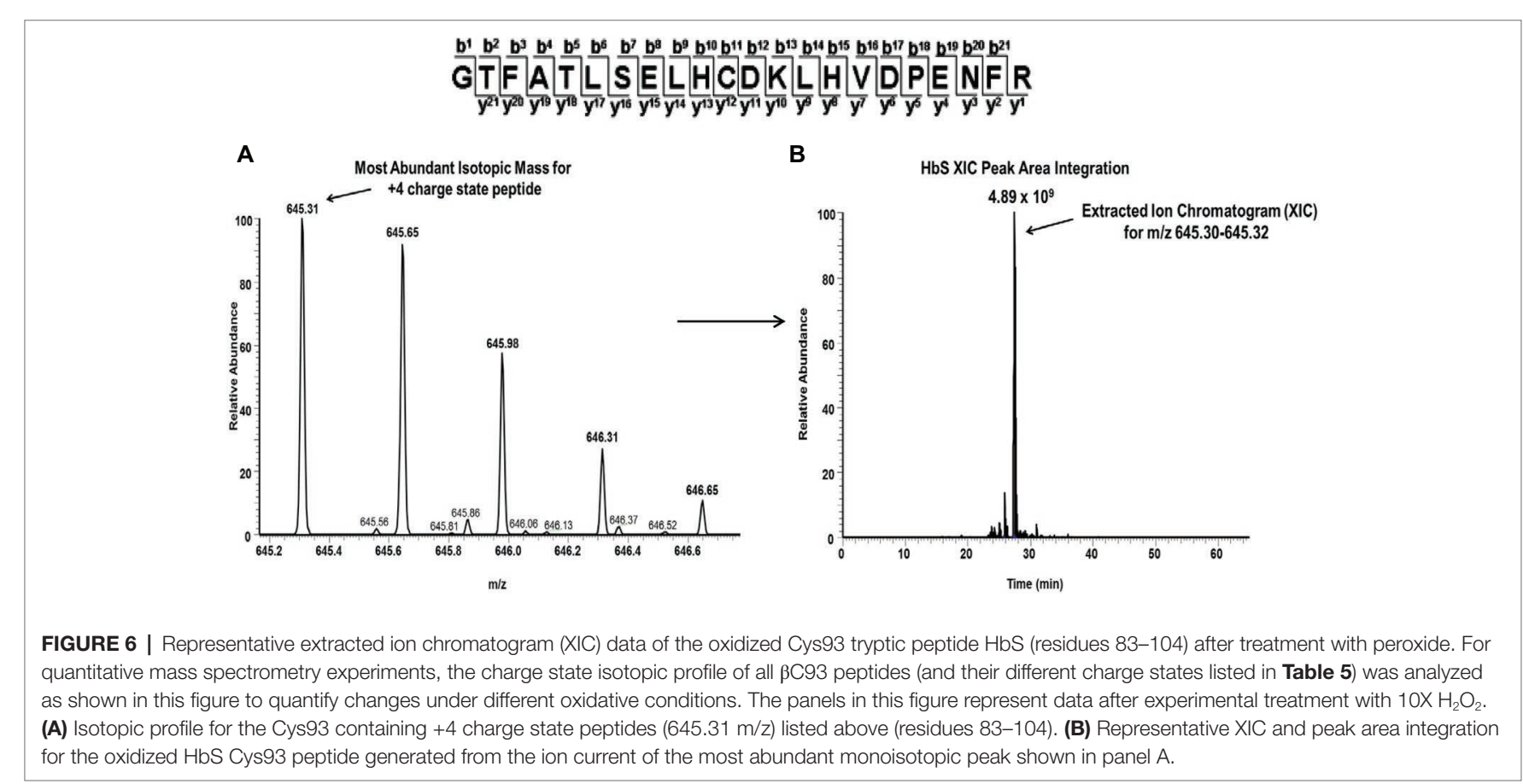


anti-adhesion agents, modulators of ischemia-reperfusion (and oxidative stress), agents that counteract free $\mathrm{Hb}$ and heme, anti-inflammatory agents, anti-thrombotic agents, and antiplatelet agents (Telen et al., 2019).

The oxidative stress is partly driven by the formation of highly oxidizing ferryl heme and its associated protein cation radicals in parent RBCs and within RBC-derived MPs (Jana et al., 2018). These internal reactions result in irreversible amino acid oxidation of the protein in the area known as "oxidative hotspots" (specifically the $\beta$ Cys93 side chain) that contribute to the partial collapse of $\beta$ subunits, unfolding and degradation of $\mathrm{Hb}$, and the ultimate release of heme. The amino acid $\beta \mathrm{Cys} 93$ occupies an important and crucial position at the $\beta / \alpha$ interface and is critically involved in the $\mathrm{Hb} \mathrm{R}$ to $\mathrm{T}$ transition. $\beta \mathrm{Cys} 93$ has been shown to be extensively and irreversibly oxidized to cysteic acid in the presence of relatively low levels of $\mathrm{H}_{2} \mathrm{O}_{2}$. Moreover, $\beta$ Cys 93 is more amenable to oxidative attack by ferryl $\mathrm{Hb}$ and its protein radicals (Jia et al., 2007).

Since $\beta$ Cys 93 plays a key role in $\mathrm{Hb}$ allosteric, antisickling, and oxidative modulation (Jia et al., 2007; Omar et al., 2015), we tested whether currently approved drugs and other compounds that are under development may provide combined antisickling and antioxidative functions by targeting $\beta$ Cys93. Toward this goal, we contrasted two sets of compounds that are known to site specifically bind/modify $\beta$ Cys93 (i.e., HU and TD3) with those that non-site specifically interacts with the protein (i.e., 5HMF and L-glutamine).

The therapeutic benefits of $\mathrm{HU}$ have been attributed to its ability to increase HbF levels in patient blood. It has also been reported that $\mathrm{HU}$ exhibits antioxidant properties by protecting patient RBCs against oxidative stress (Agil and Sadrzadeh, 2000; Nader et al., 2018). In an experiment designed to investigate potential $\mathrm{HU}$ antioxidant characteristics, HU-treated Townes sickle cell mice (fed a diet containing HU for 10 days) showed

TABLE 4 | Hydrogen peroxide mediated oxidation of $\mathrm{HbS} \beta \mathrm{C} 93$.

\begin{tabular}{lcc}
\hline $\begin{array}{l}\text { Antisickling } \\
\text { agent }+\mathbf{H b S}\end{array}$ & $\begin{array}{c}\mathbf{C 9 3} \text { ox } \\
\mathbf{2 . 5} \mathbf{X} \mathbf{~}_{\mathbf{2}} \mathbf{O}_{\mathbf{2}}\end{array}$ & $\begin{array}{c}\mathbf{C 9 3} \mathbf{~ o x} \\
\mathbf{1 0 \times} \mathbf{~}_{\mathbf{2}} \mathbf{O}_{\mathbf{2}}\end{array}$ \\
\hline $\mathrm{HbS}$ control & $36.4 \pm 1.4 \%$ & $69.1 \pm 7.3 \%$ \\
$5 \mathrm{HMF}$ & $33.1 \pm 2.7 \%$ & $61.0 \pm 0.4 \%$ \\
TD-3* & $11.8 \pm 1.8 \%$ & $12.5 \pm 0.4 \%$ \\
Hydroxyurea (HU) & $17.2 \pm 0.9 \%$ & $32.1 \pm 1.7 \%$ \\
Glutamine (GIn) & $35.0 \pm 0.1 \%$ & $67.9 \pm 1.2 \%$ \\
\hline
\end{tabular}

${ }^{*} T D-3$ modifies Cys93; these values represent oxidation from unlabeled Cys 93. a remarkable reduction in MP formation, band 3 modifications, and $\mathrm{Hb}$ posttranslational modifications (including reduction in ßCys93 oxidation) in their hemolysates (Jana et al., 2018). In the presence of $\mathrm{HU}$, a causative relationship between ferryl heme and the degree of cysteic acid formation were clearly established in our current in vitro studies consistent with these earlier observations (Jana et al., 2018). Previous in vitro and in vivo EPR studies have documented NO release from $\mathrm{HU}$ through nitrosyl $\mathrm{Hb}$ formation (Kim-Shapiro et al., 1999; Huang et al., 2002; King, 2004). We have also previously shown that $\mathrm{NO}$ released from an NO donor sodium 2-(N,N-diethylamino)diazenolate-2-oxide (DEANO) binds specifically to $\beta$ Cys93 (Hrinczenko et al., 2000). The electrospray mass spectrometry data in this study also confirm the presence of S-nitrosylation (corresponding to a 29-Da increase consistent with NO binding) of both the $\beta$ chains but not of the $\alpha$ chains. Hb S-nitrosylation at $\beta$ Cys93 has been shown to have stabilizing effects on $\mathrm{Hb}$ since it shields this amino acid from ferryl radical reactivity (Jana et al., 2018). This may provide an additional molecular interpretation for the reported efficacy of this drug in treatment of SCD (Ferrone, 2016). This newly antioxidative benefit (associated with use of $\mathrm{HU}$ ) is independent of its well-known $\mathrm{HbF}$ induction as we have documented in HU-treated patient blood who was on HU therapy regimen. The most striking finding in this work, however, is the correlation between the $\mathrm{HU}$ induced reduction in both ferryl heme and $\beta \mathrm{Cys} 93$ oxidation levels (with increasing $\mathrm{H}_{2} \mathrm{O}_{2}$ concentrations) when comparing the same experimental conditions with the HbS control.

The basis of the antisickling action of TD-3 was found to be due to a disulfide formation with $\beta$ Cys93 of HbS's $\beta$ subunit (Nakagawa et al., 2018). The crystal structure of HbACO complexed with TD-3 revealed that MT-3 (the monomer) forms a disulfide bond with the $\beta$ Cys93 side chain thiol. The nitrogen atoms of the triazole ring form a hydrogen-bond interaction and watermediated hydrogen-bond interactions with protein oxygen atom in the region. Our mass spectrometric analysis of intact and digested peptides of $\mathrm{HbS}$ confirms that TD-3 substantially modifies both $\beta$ and $\alpha$ subunits of HbS. While intact mass data indicated that the TD-3 modification stoichiometry was not $100 \%$, TD-3 provided the greatest degree of anti-oxidant protection as evidence by a sustained reduction in ferryl heme and its target $\beta$ subunit Cys93. The labeling and protection of $\beta$ C93 was further substantiated by the fact that $\beta$ C93 oxidation was substantially reduced in TD-3 treated samples (minimal oxidation observed for TD-3 treated HbS in Table 4 is due to unlabeled Cys93). This work collectively shows that TD-3 has induced changes in

TABLE 5 | Summary of antisickling and antioxidant effects of agents under oxidative stress $\left[2.5 \mathrm{H}_{2} \mathrm{O}_{2} / \mathrm{Hb}(\mathrm{Heme})\right]$.

\begin{tabular}{|c|c|c|c|c|c|}
\hline Agents & $\mathrm{O}_{2}$ affinity & Autoxidation rate & $\begin{array}{l}\text { Ferryl formation } \\
\text { (\% Reduction) }\end{array}$ & Delay time (s) & Cys93 modification \\
\hline TD-3 & Increased & No effect & Reduced (22\%) & 315 & ++ \\
\hline 5-HMF & Increased & No effect & No effect & 158 & -- \\
\hline $\mathrm{HU}$ & Increased & No effect & Reduced (38\%) & 170 & ++ \\
\hline L-Glutamine & No Effect & No effect & No effect & 158 & -- \\
\hline
\end{tabular}

Modified = ++; not modified $=--$. 
oxygen binding affinity of $\mathrm{HbS}$ and delayed polymer formation of the deoxy form of $\mathrm{Hb}$ via protective mechanisms.

Similarly, 5HMF increased the oxygen affinity and delay time of $\mathrm{HbS}$ making this molecule an ideal antisickling therapeutic. Specifically, 5HMF acts to inhibit SS cells from sickling by covalently binding to and stabilizing the $\mathrm{Hb}$ relaxed state and/or binding to and destabilizing the $\mathrm{T}$ state of $\mathrm{HbS}$ with a concomitant shift of the allosteric equilibrium to the high affinity HbS. The antisickling activity of 5HMF is primarily due to Schiff-base interactions between the aldehyde moiety and the N-terminal alpha Vall amine of Hb. Previous X-ray crystallography study supports these observations (Safo et al., 2004). Our results show that there was no change in ferryl heme levels and subsequently no change in irreversible oxidation in $\beta$ Cys 93 at low and high levels of $\mathrm{H}_{2} \mathrm{O}_{2}$-treated $\mathrm{HbS}$.

The in vitro treatment of $\mathrm{HbS}$ with L-glutamine did not show any impact on HbS oxygen affinity nor did it have any effects on Hb's chemically induced oxidation reactions. The mechanism of action of L-glutamine is believed to be due to its ability to maintain a redox balance within RBCs by increasing internal levels of NAD+. However, the safety and efficacy of L-glutamine therapy in SCD has recently been questioned (Quinn, 2018). Nevertheless, our result on the $\mathrm{Hb}$ oxidation showed that L-glutamine did not provide an antioxidant advantage reflected by our spectrophotometric oxidation data and quantitative mass spectrometry results which indicate that glutamine-treated $\mathrm{HbS} \beta \mathrm{C} 93$ oxidation was nearly identical to control data when treated with $\mathrm{H}_{2} \mathrm{O}_{2}$. We have also measured effects of these molecules, particularly glutamine on the RBC's NAD/NADH redox potential. We have carried out measurements on NADH and total NAD in RBCs treated with and without glutamine to assess the change in RBCs redox potential. Treatment of antisickling agents (including glutamine) did not result in any measurable difference in the $\mathrm{NADH} /$ total $\mathrm{NAD}$ ratio between treated/untreated SCD RBC control (unpublished data). It is known that there is an ongoing debate and many unanswered questions regarding glutamine's efficacy, safety, and its role in current therapy (Quinn, 2018). We therefore feel that targeting Hb's own oxidative pathways (specifically $\beta$ Cys93) are more predictive of the overall status of the RBC's redox state.

In summary, here we show that all four antisickling agents provide some level of antisickling activity (see Table 5).

\section{REFERENCES}

Abdulmalik, O., Safo, M. K., Chen, Q., Yang, J., Brugnara, C., Ohene-Frempong, K., et al. (2005). 5-Hydroxymethyl-2-furfural modifies intracellular sickle haemoglobin and inhibits sickling of red blood cells. Br. J. Haematol. 128, 552-561. doi: 10.1111/j.1365-2141.2004.05332.x

Agil, A., and Sadrzadeh, S. M. (2000). Hydroxy-urea protects erythrocytes against oxidative damage. Redox Rep. 5, 29-34. doi: 10.1179/rer.2000.5.1.29

Alayash, A. I. (2018). Oxidative pathways in the sickle cell and beyond. Blood Cells Mol. Dis. 70, 78-86. doi: 10.1016/j.bcmd.2017.05.009

Berzofsky, J. A., Peisach, J., and Blumberg, W. E. (1971). Sulfheme proteins. I. Optical and magnetic properties of sulfmyoglobin and its derivatives. J. Biol. Chem. 246, 3367-3377.

Eaton, W. A., and Bunn, H. F. (2017). Treating sickle cell disease by targeting HbS polymerization. Blood 129, 2719-2726. doi: 10.1182/ blood-2017-02-765891
In particular, those antisickling drugs that directly modify $\beta$ Cys93 effectively protect this "hotspot" amino acid from irreversible oxidation by a strong oxidant, such as ferryl heme and simultaneously prolong the delay time prior to the formation of the polymer. Photometric and mass spectrometric studies showed a strong relationship between the levels of ferryl heme and oxidative changes in the $\mathrm{Hb}$ molecule. Shielding of $\beta$ Cys93 by these reagents likely prevented the escape of the ferryl radical through this amino acid (Kassa et al., 2015), lessening therefore consequent oxidative damages to the protein. Hence, our results suggest that agents targeting $\beta$ Cys 93 of $\mathrm{HbS}$ can potentially provide both antisickling and antioxidant therapeutic advantages for patients with SCD.

\section{DATA AVAILABILITY}

The raw data supporting the conclusions of this manuscript will be made available by the authors, without undue reservation, to any qualified researcher.

\section{AUTHOR CONTRIBUTIONS}

TK and AA designed the work. TK, MS, and FW performed the experiments and data analysis. TK and AA contributed to conception and design. TK, MS, and AA wrote and edited the manuscript.

\section{FUNDING}

This work was supported by the National Institutes of Health (NIH/NHLBI) under grant HL110900 (AA) and by the U.S. Food and Drug Administration (MODSCI) to (AA).

\section{ACKNOWLEDGMENTS}

The authors would like to thank Dr. Warren Zapol of Massachusetts General Hospital and Harvard Medical School for providing TD-3.

Ferrone, F. A. (2016). Sickle cell disease: its molecular mechanism and the one drug that treats it. Int. J. Biol. Macromol. 93, 1168-1173. doi: 10.1016/j. ijbiomac.2016.09.073

George, A., Pushkaran, S., Konstantinidis, D. G., Koochaki, S., Malik, P., Mohandas, N., et al. (2013). Erythrocyte NADPH oxidase activity modulated by Rac GTPases, PKC, and plasma cytokines contributes to oxidative stress in sickle cell disease. Blood 121, 2099-2107. doi: 10.1182/ blood-2012-07-441188

Hebbel, R. P., Morgan, W. T., Eaton, J. W., and Hedlund, B. E. (1988). Accelerated autoxidation and heme loss due to instability of sickle hemoglobin. Proc. Natl. Acad. Sci. USA 85, 237-241.

Hrinczenko, B. W., Schechter, A. N., Wojtkowski, T. L., Pannell, L. K., Cashon, R. E., and Alayash, A. I. (2000). Nitric oxide-mediated heme oxidation and selective beta-globin nitrosation of hemoglobin from normal and sickle erythrocytes. Biochem. Biophys. Res. Commun. 275, 962-967. doi: 10.1006/bbrc.2000.3413 
Huang, J., Hadimani, S. B., Rupon, J. W., Ballas, S. K., Kim-Shapiro, D. B., and King, S. B. (2002). Iron nitrosyl hemoglobin formation from the reactions of hemoglobin and hydroxyurea. Biochemistry 41, 2466-2474. doi: 10.1021/ bi011470o

Jagadeeswaran, R., Vazquez, B. A., Thiruppathi, M., Ganesh, B. B., Ibanez, V., Cui, S., et al. (2017). Pharmacological inhibition of LSD1 and mTOR reduces mitochondrial retention and associated ROS levels in the red blood cells of sickle cell disease. Exp. Hematol. 50, 46-52. doi: 10.1016/j.exphem.2017.02.003

Jana, S., Strader, M. B., Meng, F., Hicks, W., Kassa, T., Tarandovskiy, I., et al. (2018). Hemoglobin oxidation-dependent reactions promote interactions with band 3 and oxidative changes in sickle cell-derived microparticles. JCI Insight 3:120451. doi: 10.1172/jci.insight.120451

Jia, Y., Buehler, P. W., Boykins, R. A., Venable, R. M., and Alayash, A. I. (2007). Structural basis of peroxide-mediated changes in human hemoglobin: a novel oxidative pathway. J. Biol. Chem. 282, 4894-4907. doi: 10.1074/jbc. M609955200

Kassa, T., Jana, S., Strader, M. B., Meng, F., Jia, Y., Wilson, M. T., et al. (2015). Sickle cell hemoglobin in the ferryl state promotes betaCys-93 oxidation and mitochondrial dysfunction in epithelial lung cells (E10). J. Biol. Chem. 290, 27939-27958. doi: 10.1074/jbc.M115.651257

Kassa, T., Strader, M. B., Nakagawa, A., Zapol, W. M., and Alayash, A. I. (2017). Targeting betaCys93 in hemoglobin S with an antisickling agent possessing dual allosteric and antioxidant effects. Metallomics 9, 1260-1270. doi: 10.1039/C7MT00104E

Keller, A., Nesvizhskii, A. I., Kolker, E., and Aebersold, R. (2002). Empirical statistical model to estimate the accuracy of peptide identifications made by MS/MS and database search. Anal. Chem. 74, 5383-5392. doi: 10.1021/ac025747h

Kim-Shapiro, D. B., King, S. B., Shields, H., Kolibash, C. P., Gravatt, W. L., and Ballas, S. K. (1999). The reaction of deoxy-sickle cell hemoglobin with hydroxyurea. Biochim. Biophys. Acta 1428, 381-387.

King, S. B. (2004). Nitric oxide production from hydroxyurea. Free Radic. Biol. Med. 37, 737-744. doi: 10.1016/j.freeradbiomed.2004.02.073

Mahaseth, H., Vercellotti, G. M., Welch, T. E., Bowlin, P. R., Sonbol, K. M., Hsia, C. J., et al. (2005). Polynitroxyl albumin inhibits inflammation and vasoocclusion in transgenic sickle mice. J. Lab. Clin. Med. 145, 204-211. doi: 10.1016/j.lab.2005.02.008

Meng, F., and Alayash, A. I. (2017). Determination of extinction coefficients of human hemoglobin in various redox states. Anal. Biochem. 521, 11-19.

Meng, F., Kassa, T., Strader, M. B., Soman, J., Olson, J. S., and Alayash, A. I. (2019). Substitutions in the beta subunits of sickle-cell hemoglobin improve oxidative stability and increase the delay time of sickle-cell fiber formation. J. Biol. Chem. 294, 4145-4159. doi: 10.1074/jbc.RA118.006452

Mozzarelli, A., Hofrichter, J., and Eaton, W. A. (1987). Delay time of hemoglobin $\mathrm{S}$ polymerization prevents most cells from sickling in vivo. Science 237, 500-506. doi: 10.1126/science. 3603036

Nader, E., Grau, M., Fort, R., Collins, B., Cannas, G., Gauthier, A., et al. (2018). Hydroxyurea therapy modulates sickle cell anemia red blood cell physiology: impact on RBC deformability, oxidative stress, nitrite levels and nitric oxide synthase signalling pathway. Nitric Oxide 81, 28-35. doi: 10.1016/j. niox.2018.10.003

Nakagawa, A., Ferrari, M., Schleifer, G., Cooper, M. K., Liu, C., Yu, B., et al. (2018). A triazole disulfide compound increases the affinity of hemoglobin for oxygen and reduces the sickling of human sickle cells. Mol. Pharm. 15, 1954-1963. doi: 10.1021/acs.molpharmaceut.8b00108

Nakagawa, A., Lui, F. E., Wassaf, D., Yefidoff-Freedman, R., Casalena, D., Palmer, M. A., et al. (2014). Identification of a small molecule that increases hemoglobin oxygen affinity and reduces SS erythrocyte sickling. ACS Chem. Biol. 9, 2318-2325. doi: 10.1021/cb500230b

Niihara, Y., Zerez, C. R., Akiyama, D. S., and Tanaka, K. R. (1997). Increased red cell glutamine availability in sickle cell anemia: demonstration of increased active transport, affinity, and increased glutamate level in intact red cells. J. Lab. Clin. Med. 130, 83-90. doi: 10.1016/S0022-2143(97)90062-7

Omar, A. M., Mahran, M. A., Ghatge, M. S., Chowdhury, N., Bamane, F. H., El-Araby, M. E., et al. (2015). Identification of a novel class of covalent modifiers of hemoglobin as potential antisickling agents. Org. Biomol. Chem. 13, 6353-6370. doi: 10.1039/C5OB00367A

Pimenova, T., Pereira, C. P., Gehrig, P., Buehler, P. W., Schaer, D. J., and Zenobi, R. (2010). Quantitative mass spectrometry defines an oxidative hotspot in hemoglobin that is specifically protected by haptoglobin. J. Proteome Res. 9, 4061-4070. doi: 10.1021/pr100252e

Quinn, C. T. (2018). L-glutamine for sickle cell anemia: more questions than answers. Blood 132, 689-693. doi: 10.1182/blood-2018-03-834440

Rees, D. C., Williams, T. N., and Gladwin, M. T. (2010). Sickle-cell disease. Lancet 376, 2018-2031. doi: 10.1016/S0140-6736(10)61029-X

Riley, T. R., Boss, A., Mcclain, D., and Riley, T. T. (2018). Review of medication therapy for the prevention of sickle cell crisis. $P T 43,417-437$.

Safo, M. K., Abdulmalik, O., Danso-Danquah, R., Burnett, J. C., Nokuri, S. Joshi, G. S., et al. (2004). Structural basis for the potent antisickling effect of a novel class of five-membered heterocyclic aldehydic compounds. J. Med. Chem. 47, 4665-4676. doi: 10.1021/jm0498001

Strader, M. B., and Alayash, A. I. (2017). Exploring oxidative reactions in hemoglobin variants using mass spectrometry: lessons for engineering oxidatively stable oxygen therapeutics. Antioxid. Redox Signal. 26, 777-793. doi: 10.1089 /ars.2016.6805

Strader, M. B., Hicks, W. A., Kassa, T., Singleton, E., Soman, J., Olson, J. S., et al. (2014). Post-translational transformation of methionine to aspartate is catalyzed by heme iron and driven by peroxide: a novel subunit-specific mechanism in hemoglobin. J. Biol. Chem. 289, 22342-22357. doi: 10.1074/ jbc.M114.568980

Telen, M. J., Malik, P., and Vercellotti, G. M. (2019). Therapeutic strategies for sickle cell disease: towards a multi-agent approach. Nat. Rev. Drug Discov. 18, 139-158. doi: 10.1038/s41573-018-0003-2

Conflict of Interest Statement: The authors declare that the research was conducted in the absence of any commercial or financial relationships that could be construed as a potential conflict of interest.

Copyright (c) 2019 Kassa, Wood, Strader and Alayash. This is an open-access article distributed under the terms of the Creative Commons Attribution License (CC BY). The use, distribution or reproduction in other forums is permitted, provided the original author(s) and the copyright owner(s) are credited and that the original publication in this journal is cited, in accordance with accepted academic practice. No use, distribution or reproduction is permitted which does not comply with these terms. 